\title{
Whole-Cell Plasticity in Cocaine Withdrawal: Reduced Sodium Currents in Nucleus Accumbens Neurons
}

\author{
Xu-Feng Zhang, Xiu-Ti Hu, and Francis J. White \\ Neuropsychopharmacology Laboratory, Department of Neuroscience, Finch University of Health Sciences/The Chicago \\ Medical School, North Chicago, Illinois 60064-3095
}

\begin{abstract}
The nucleus accumbens is a forebrain region that mediates cocaine self-administration and withdrawal effects in animal models of cocaine dependence. Considerable evidence suggests an important role of dopamine D1 receptors in these effects. Using a combination of current-clamp recordings in brain slices and whole-cell patch-clamp recordings from freshly dissociated neurons, we found that nucleus accumbens neurons are less excitable in cocaine withdrawn rats because of a novel form of plasticity: reduced whole-cell sodium currents. Three days after discontinuation of repeated cocaine injections, nucleus accumbens neurons recorded in brain slices were less responsive to depolarizing current injections, had higher action potential thresholds, and had lower spike amplitudes. Freshly dissociated nucleus accumbens neurons from cocainepretreated rats exhibited diminished sodium current density and a depolarizing shift in the voltage-dependence of sodium
\end{abstract}

channel activation. These effects appear to be related to enhanced basal phosphorylation of sodium channels because of increased transmission through the dopamine D1 receptor/ cAMP-dependent protein kinase pathway. The effects of repeated cocaine administration were not mimicked by repeated injections of the local anesthetic lidocaine and were not observed in neurons within the motor cortex, indicating that they did not result from local anesthetic actions of cocaine. Because nucleus accumbens neurons are normally recruited to coordinate response patterns of movement and affect, the decreased excitability during cocaine withdrawal may be related to symptoms such as anergia, anhedonia, and depression.

Key words: nucleus accumbens; cocaine addiction; dopamine D1 receptors; sodium channels; patch clamp; whole-cell plasticity
Despite widespread awareness of the addictive potential of cocaine, abuse of this illicit drug remains one of our foremost public health problems (Cornish and O'Brien, 1996). Cocaine dependence is typically associated with cyclical patterns of binge-type abuse and abstinence (Gawin, 1991). During abstinence, there are periods of intense cocaine craving and other withdrawal symptoms, such as anergia, anhedonia, and depression, which play significant roles in relapse (Gawin, 1991; Kleber, 1995). The primary neurochemical action of cocaine is to potentiate synaptic transmission from dopamine (DA) and other monoaminecontaining (serotonin and norepinephrine) neurons by preventing those neurons from recapturing released neurotransmitter (for review, see Galloway, 1992). Cocaine prevents reuptake by binding to specific receptor sites on the different monoamine transporter proteins (for review, see Reith, 1992). At higher doses, cocaine can also produce local anesthetic effects by a usedependent block of voltage-sensitive sodium channels (VSSCs) (Postma and Catterall, 1984; Reith et al., 1986), shifting the voltage dependence of inactivation in the hyperpolarizing direction (Wang and Wang, 1992).

Among the various neurochemical actions of cocaine, block-

Received July 3, 1997; revised Sept. 24, 1997; accepted Oct. 17, 1997.

This work was supported by United States Public Health Service Grant DA04093 and Research Scientist Development Award DA00207 from the National Institute on Drug Abuse (NIDA) to F.J.W. We thank Lorinda Baker for excellent technical assistance, and D. Cooper, R. Hawkins, and M. Wolf for helpful comments on this manuscript. Cocaine was provided by the Research Technology Branch of the NIDA.

Correspondence should be addressed to Dr. Francis J. White, Department of Neuroscience, Finch University of Health Sciences/The Chicago Medical School, 3333 Green Bay Road, North Chicago, IL 60064-3095.

Copyright $\odot 1997$ Society for Neuroscience $0270-6474 / 97 / 180488-11 \$ 05.00 / 0$ ing the DA transporter is most highly associated with reinforcing (hedonic) efficacy (Ritz et al., 1987). Animal models of cocaine dependence have identified specific DA neuronal systems projecting from the ventral tegmental area (VTA) to the nucleus accumbens (NAc) and related limbic and cortical areas as being primarily responsible for cocaine self-administration and at least partially responsible for cocaine withdrawal (for review, see Koob and Bloom, 1988; Koob, 1992; Kuhar and Pilotte, 1996; Wise, 1996). Although several cellular and molecular alterations have been identified within the VTA-NAc neural system both in animals (for review, see Self and Nestler, 1995; Hyman, 1996; Kuhar and Pilotte, 1996) and in humans (Volkow and Fowler, 1995), pharmacotherapies targeted at such changes have yet to be proven effective in cocainedependent individuals (Gawin, 1991; Kleber, 1995; Cornish and O'Brien, 1996). This likely reflects an incomplete understanding of neuroadaptations that result from repeated cocaine use (Self and Nestler, 1995; Hyman, 1996).

Over the past several years, we have used in vivo electrophysiological recordings of single NAc neurons to identify timedependent alterations in responsiveness to cocaine, DA, and other neurotransmitters after repeated cocaine administration (Henry and White, 1991,1995; White et al., 1992,1995a,b). We have demonstrated a close temporal relationship between the persistence of one well established behavioral consequence of repeated cocaine administration, sensitization, and enhanced responsiveness of NAc neurons to stimulation of the D1 class of DA receptors (Henry and White, 1991,1995). Additional NAc neuronal alterations are evident at early withdrawal times, including enhanced inhibitory effects of GABA and serotonin (White et al., 
1992; Henry and White, 1995) and markedly attenuated excitatory responses to glutamate (White et al., 1995b). Some of these changes were tested after longer withdrawal times (GABA, serotonin) and found to be transient, lasting $<7 \mathrm{~d}$. Because there is no evidence to suggest that cocaine dependence alters receptor systems for all of these neurotransmitters within the NAc, we considered the possibility that modifications had occurred in the intrinsic membrane properties of NAc neurons. Here we demonstrate that during the early period of withdrawal from repeated administration of cocaine, there is a marked decrease in the excitability of NAc neurons resulting from reduced conductance through VSSCs.

\section{MATERIALS AND METHODS}

Animals and treatments. Adult male Sprague Dawley rats initially weighing 150-175 gm were housed in groups of two to four in a temperatureand humidity-controlled vivarium under a $12 \mathrm{hr}$ light/dark cycle. Food and water were freely available. After a 1 week acclimation to the vivarium, rats either were used for acute experiments regarding sodium current modulation or randomly assigned to one of three groups that received once daily intraperitoneal injections of saline $(1.0 \mathrm{ml} / \mathrm{kg}),(-)$ cocaine $\mathrm{HCl}(15.0 \mathrm{mg} / \mathrm{kg})$, or lidocaine $\mathrm{HCl}(50.0 \mathrm{mg} / \mathrm{kg})$ for 5 consecutive days. Drug doses are given as the $\mathrm{HCl}$ salts. All experiments were conducted on the third day after cessation of injections.

Brain slice recordings. All procedures were in strict accordance with the Guide for the Care and Use of Laboratory Animals (National Institutes of Health Publication No. 85-23) and were approved by our Institutional Animal Care and Use Committee. Rats were decapitated under halothane anesthesia, and brains were rapidly excised and dissected into blocks $(3-4 \mathrm{~mm})$ containing the NAc. The blocks of tissue were immersed in ice-cold artificial cerebrospinal fluid (ACSF) [(in mM): $\mathrm{NaCl}$ 124, $\mathrm{KCl} 5, \mathrm{MgSO}_{4} 2, \mathrm{NaH}_{2} \mathrm{PO}_{4} 1.25, \mathrm{NaHCO}_{3} 26, \mathrm{CaCl}_{2} 2.4$, and D-glucose $10, \mathrm{pH} 7.4 \pm 0.05$ ] and sectioned in the coronal plane with a motorized vibrating microtome. Brain slices were transferred to a holding chamber and incubated in oxygenated $\left(95 \% \mathrm{O}_{2}: 5 \% \mathrm{CO}_{2}\right)$ ACSF for at least $60 \mathrm{~min}$ before experimentation. Slices were then transferred to an interface-type recording chamber where they rested on nylon mesh and were superfused continuously with warm $\left(35-36^{\circ} \mathrm{C}\right)$ oxygenated ACSF (flow rates of 1-2 $\mathrm{ml} / \mathrm{min}$ ). Borosilicate glass capillaries were pulled (tip diameter $<1 \mu \mathrm{m}$ ) and filled with $3 \mathrm{~m}$ potassium acetate (resistance: $70-150 \mathrm{M} \Omega)$. Current-voltage ( $I-V)$ relationships were studied by injecting step constant current pulses ( $100 \mathrm{msec}$ duration, -0.8 to $+1.5 \mathrm{nA}$ ) through the recording electrode using the active bridge circuit of an Axoclamp 2A amplifier (Axon Instruments, Foster City, CA). Electrical activity was first amplified by a head stage located near the slice before being amplified and distributed to an oscilloscope and a 486-based computer running pCLAMP software (Axon Instruments). Recordings were made primarily from the core region of the NAc, although shell neurons were also included. As detailed previously (O'Donnell and Grace, 1993), we observed no difference in the membrane properties of shell and core neurons.

Whole-cell recordings. NAc neurons were freshly dissociated from slices obtained from rats $(100-150 \mathrm{gm})$ as described above. Slices were cut while bathed in a low $\mathrm{Ca}^{2+}(100 \mu \mathrm{M})$, HEPES-buffered salt solution (in $\mathrm{mM}$ ): 140 sodium isethionate, $2 \mathrm{KCl}, 4 \mathrm{MgCl}_{2}, 0.1 \mathrm{CaCl}_{2}, 23$ glucose, 15 mM HEPES, $\mathrm{pH} 7.4,300-305 \mathrm{mOsm} / \mathrm{l})$. Slices were then incubated for 1-6 hr at room temperature in a $\mathrm{NaHCO}_{3}$-buffered saline (Earle's Balanced Salts solution), bubbled with $95 \% \mathrm{O}_{2}, 5 \% \mathrm{CO}_{2}$. Slices were then removed into the low $\mathrm{Ca}^{2+}$ buffer, and with the aid of a dissecting microscope, the NAc (including both core and shell regions) was micropunched and placed in an oxygenated stir chamber containing pronase $(1-1.5 \mathrm{mg} / \mathrm{ml})$ in HEPES-buffered HBSS at $35^{\circ} \mathrm{C}$. After $20-30 \mathrm{~min}$ of enzyme digestion, tissue was rinsed three times in the low $\mathrm{Ca}^{2+}$, HEPES-buffered saline and mechanically dissociated with a graded series of fire-polished Pasteur pipettes. The cell suspension was then plated into a petri dish mounted on the stage of an inverted microscope containing $1 \mathrm{ml}$ of HEPES-buffered HBSS. After the cells were allowed to settle, the solution bathing the cells was changed to our normal recording external solution.

Whole-cell recordings used standard techniques. Electrodes were pulled from Corning 7052 glass capillaries and fire-polished before use. Sodium current was isolated by using the following solutions: internal (in
mM) $120 \mathrm{CsF}, 10 \mathrm{NaCl}, 10$ EGTA, $2 \mathrm{Na}_{2} \mathrm{ATP}, 10$ HEPES, pH 7.3 , 265-270 mOsm/l; external (in mM) $100 \mathrm{NaCl}, 30$ choline chloride, 5 CsCl, $1 \mathrm{MgCl}_{2}, 1 \mathrm{CaCl}_{2}, 0.4 \mathrm{CdCl}_{2}, 10$ glucose, 10 HEPES, pH 7.4, 300-305 mOsm/1. Electrodes filled with this solution had a resistance of 2-4 M $\Omega$ when tested in the bath solution. The junction potential of -5 $\mathrm{mV}$ was measured between the electrode and bath solution and was not compensated. Recordings were obtained with an Axon Instruments 200A patch-clamp amplifier and controlled and monitored with a PC 486 running pCLAMP6 with a $2 \mathrm{kHz}$ filter. Step depolarizing pulses were applied at intervals of 5-10 sec to allow enough time for $\mathrm{Na}^{+}$channels to recover from inactivation. After seal rupture, series resistance $(<10 \mathrm{M} \Omega)$ was compensated $(70-80 \%)$ and periodically monitored. All currents were leak-subtracted. Adequate voltage control was determined by standard methods (Colatsky and Tsien, 1979). Recordings were made only from medium-sized neurons (6-12 $\mu \mathrm{m}$ somal diameter) that had only a few short proximal dendrites. Drugs were applied with a DAD-12 superfusion system that allowed rapid application and removal of drugs (ALA Scientific Instruments, Westbury, NY). All experiments were performed at room temperature $\left(20-22^{\circ} \mathrm{C}\right)$. To record from freshly dissociated cortical neurons, we dissected the superficial layers (1-3) of the frontoparietal motor cortex. All procedures were as described for NAc neurons, except that the external $\mathrm{Na}^{+}$concentration was decreased to $30 \mathrm{~mm}$ because of larger currents evoked in the cortical neurons. Choline chloride was increased to compensate the reduced osmolarity.

\section{RESULTS}

\section{Cocaine pretreatment alters the membrane properties of NAc neurons}

To examine the membrane properties of NAc neurons in cocainepretreated rats, we first made intracellular recordings from rat brain slices in vitro. Cocaine-pretreated NAc neurons exhibited a number of significant alterations in passive and active membrane properties, as compared with saline-pretreated controls (Table 1). Resting membrane potentials were hyperpolarized, action potential generation by depolarizing current injection required higher current intensities (rheobase), $\mathrm{Na}^{+}$spike thresholds were increased, and spike amplitudes were reduced. In many neurons, the afterhyperpolarization amplitudes were also increased, but variability in this measure precluded it from reaching statistical significance (Table 1, Fig. 1). Figure 1 shows examples of action potentials obtained from control and cocaine-pretreated neurons such that the decreased spike amplitudes of cocaine-treated neurons can be appreciated. Taken together, these findings indicate that the excitability of NAc neurons is significantly reduced by repeated cocaine administration.

Although the absolute magnitude $(<20 \%)$ of certain changes [resting membrane potential (RMP), action potential threshold and amplitude] may appear small (Table 1), they are not only statistically reliable but also likely to have considerable functional impact. These alterations are likely to diminish markedly the responsiveness of NAc neurons to excitatory inputs and thus the normal output of the NAc. Alterations in RMP and threshold would result in the need for greater excitatory barrage, because under normal circumstances, maintained coordinated synaptic activation is required to depolarize medium spiny neurons to the point of spike activity (O'Donnell and Grace, 1995; Wilson and Kawaguchi, 1996). Moreover, the more hyperpolarized resting state of the neurons will decrease the likelihood of firing by maintaining the slowly inactivating potassium channel in a noninactivated state (Nisenbaum et al., 1994). Even when firing, the reductions in spike amplitude will diminish transmitter release substantially (Charlton and Bittner, 1978; Baxter and Bittner, 1981). To appreciate the magnitude of the changes in such membrane properties observed in our experiments, they should be compared with those produced by other in vivo manipulations on medium spiny neurons as well as with effects of repeated cocaine 


\begin{tabular}{|c|c|c|c|}
\hline & Saline & Cocaine & Lidocaine \\
\hline Number of neurons & 36 & 29 & 14 \\
\hline Number of rats & 25 & 19 & 4 \\
\hline \multicolumn{4}{|l|}{ Passive membrane properties } \\
\hline RMP (mV) & $-79.1 \pm 0.8$ & $-83.8 \pm 0.6^{* *}$ & $-76.9 \pm 1.5$ \\
\hline$R_{\text {in }}(\mathrm{m} \Omega)$ & $38.3 \pm 3.1$ & $42.4 \pm 3.1$ & $32.1 \pm 2.9$ \\
\hline Time constant $(\tau$, msec $)$ & $5.6 \pm 0.5$ & $4.7 \pm 0.8$ & $5.9 \pm 1.3$ \\
\hline \multicolumn{4}{|l|}{ Active membrane properties } \\
\hline Current to generate AP (nA) & $0.65 \pm 0.03$ & $0.96 \pm 0.06^{* *}$ & $0.69 \pm 0.09$ \\
\hline AP threshold $(\mathrm{mV})$ & $-46.7 \pm 1.5$ & $-40.9 \pm 1.7^{*}$ & $-46.1 \pm 2.1$ \\
\hline AP amplitude (mV) & $61.1 \pm 1.1$ & $52.5 \pm 1.7^{* *}$ & $59.2 \pm 1.2$ \\
\hline AP duration (msec) & $2.1 \pm 0.1$ & $2.2 \pm 0.1$ & $1.5 \pm 0.1^{*}$ \\
\hline AHP amplitude (mV) & $10.3 \pm 0.6$ & $12.8 \pm 1.0$ & $11.7 \pm 1.0$ \\
\hline
\end{tabular}

Intracellular recording was used to measure the membrane properties of nucleus accumbens neurons from brain slices obtained from the three groups of rats. Values represent the mean \pm SEM for the number of neurons indicated $(* p<0.05$; ${ }^{* *} p<0.01$; with Student's $t$ test used to compare with control). Resting membrane potential (RMP) was measured in the absence of injected current before the initiation of other manipulations. Apparent input resistance $\left(R_{\text {in }}\right)$ and time constants were determined by the membrane potential changes induced by hyperpolarizing current pulses, with the aid of algorithms within the pCLAMP software. Action potentials (APs) were generated by injecting step depolarizing current pulses of 0.1 $\mathrm{nA}$ increments. AP characteristics were obtained from the initial spike evoked by the minimal depolarizing current pulse in every NAc neuron recorded; amplitudes were measured from the spike threshold. After hyperpolarization (AHP) amplitudes were measured from the equipotential point of the spike threshold to the maximum deflection of the hyperpolarization after the end of the AP. AP duration was measured at the broadest point of the AP.

\section{Reduced $\mathrm{Na}^{+}$Spike Amplitude}

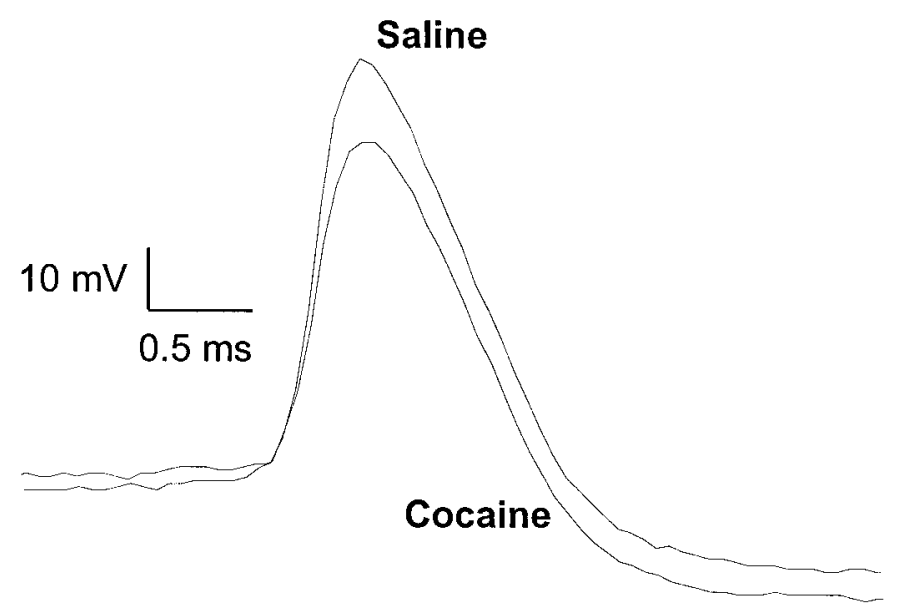

Figure 1. Repeated cocaine administration reduces action potential amplitudes of NAc neurons. Representative traces showing action potentials recorded from NAc neurons in saline-pretreated and cocaine-pretreated rats on the third day of withdrawal. Note the reduced amplitude of the action potential in the cocaine-pretreated neuron. The traces are normalized for action potential thresholds, which were $-40.2 \mathrm{mV}$ in the control neuron and $-45.0 \mathrm{mV}$ in the cocaine neuron. Resting membrane potentials were $-79 \mathrm{mV}$ for control and $-86 \mathrm{mV}$ for cocaine. Action potentials were evoked with intracellular depolarizing current injection (0.7 and 0.9 $\mathrm{nA}$ for saline and cocaine, respectively).

on other brain neurons. The changes that we observed after repeated cocaine administration are similar in magnitude to those observed in medium spiny striatal neurons 1-5 hr after transient forebrain ischemia $(\mathrm{Xu}, 1995)$ and are larger than those produced by repeated cocaine administration on the membrane properties of dorsolateral septal nucleus neurons (Simms and Gallagher, 1996; Shoji et al., 1997).

The reduction in excitability of NAc neurons by repeated cocaine administration cannot be attributed to the local anesthetic properties of cocaine because it is unlikely that cocaine or its metabolites were present in the slice after a $3 \mathrm{~d}$ withdrawal period and extensive superfusion of the slice. Moreover, repeated administration of the local anesthetic lidocaine $(50 \mathrm{mg} / \mathrm{kg}$ for $5 \mathrm{~d}$ ), which lacks significant activity at monoamine transporters (Ritz et al., 1987), failed to mimic any of the effects observed with repeated cocaine (Table 1 ).

Because D1 receptor-mediated responses are significantly enhanced by this cocaine pretreatment regimen (Henry and White, 1991) and because D1 receptor stimulation can hyperpolarize medium spiny NAc neurons (Uchimura et al., 1986; Uchimura and North, 1990), increase rheobase (O'Donnell and Grace, 1996), and reduce action potential amplitude (Schiffmann et al., 1995), we next determined whether endogenous DA within the slice had rendered NAc neurons less excitable by stimulating supersensitive D1 receptors. Bath perfusion with the selective D1 receptor antagonist SCH $23390(1-2 \mu \mathrm{M})$ did not alter the membrane properties of NAc neurons recorded from cocainepretreated rats ( $n=5$; data not shown), indicating that there was no basal activation of D1 receptors in our slices.

\section{$\mathrm{Na}^{+}$currents in NAc neurons are decreased by D1 receptor stimulation}

Computer modeling coupled to direct observations of motoneurons indicates that alterations in rheobase, spike threshold, and spike amplitude can occur with reductions in $\mathrm{Na}^{+}$conductance (Halter et al., 1995). In medium spiny neurons of the dorsal striatum, both fast and slowly inactivating $\mathrm{Na}^{+}$conductances are modulated by DA receptors (Surmeier et al., 1992; Cepeda et al., 1995; Schiffmann et al., 1995). Given the marked alterations in synaptic DA levels (and thus DA receptor activation) that occur 


\section{D1 Receptor Modulation of $\mathrm{Na}^{+}$Current}

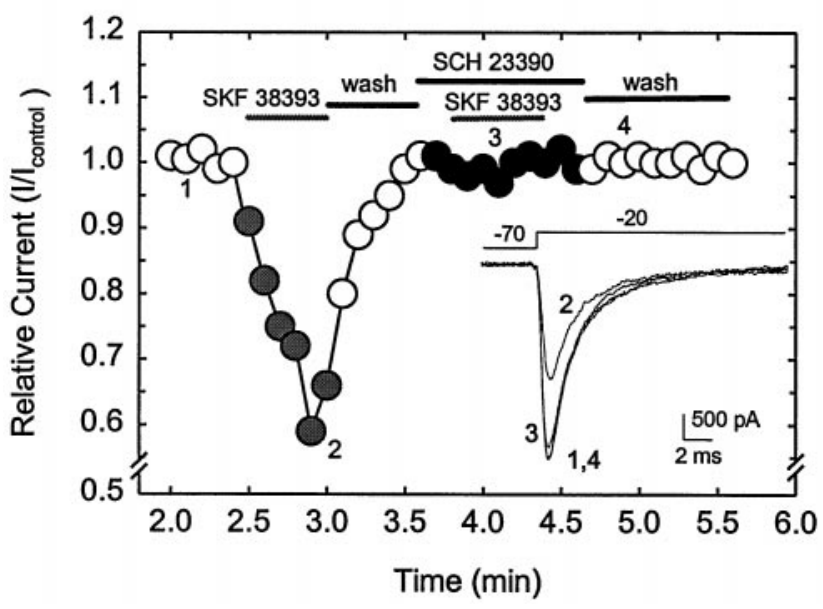

Figure 2. Stimulation of dopamine D1 receptors suppresses whole-cell $\mathrm{Na}^{+}$currents in NAc neurons. Current traces (inset) and time course showing that the D1 receptor selective agonist SKF $38393(1 \mu \mathrm{M})$ reversibly suppressed whole-cell $\mathrm{Na}^{+}$current in an untreated NAc neuron. The effect was observed in 33/40 neurons tested (mean $\pm \mathrm{SEM}=24.5 \pm 2.1 \%$ suppression; see Fig. 8 for concentration-effect curves). The dopamine D1 receptor-selective antagonist SCH $23390(1 \mu \mathrm{M})$ completely prevented the suppression of current by SKF $38393(n=6)$. Currents were evoked by stepping the membrane from the holding potential of $-70 \mathrm{mV}$ to the test potential of $-20 \mathrm{mV}$ (see protocol above traces) where $\mathrm{Na}^{+}$current was near-maximal $\left(I-V\right.$ tests not shown). $\mathrm{Na}^{+}$currents were completely prevented by tetrodotoxin (1-2 $\mu \mathrm{M}$; not shown), exhibited a reversal potential of $\sim 50 \mathrm{mV}$, and inactivated rapidly. The number associated with each trace indicates the point during the time course at which the trace was obtained.

with repeated cocaine administration (Weiss et al., 1992; Kalivas and Duffy, 1993), we reasoned that alterations may have occurred in the steady state of VSSCs modulated by DA receptors. The remainder of our study focused on this possibility. First, we determined whether $\mathrm{Na}^{+}$currents in medium spiny neurons of the NAc, like those in the dorsal striatum, are modulated by D1 receptors.

We used the whole-cell configuration of the patch-clamp technique to record $\mathrm{Na}^{+}$currents from freshly dissociated NAc neurons. Medium spiny NAc neurons (those with capacitance $<10 \mathrm{pF}$ ) (Surmeier et al., 1992) exhibited DA receptor modulation of VSSCs that was identical to that reported for the dorsal striatum (Surmeier et al., 1992; Cepeda et al., 1995; Schiffmann et al., 1995). Stimulation of D2 class receptors with the selective agonist quinpirole exerted mixed effects on whole-cell $\mathrm{Na}^{+}$currents, increasing conductance in some neurons but decreasing it in others (White et al., 1997). In contrast, D1 receptor stimulation with SKF $38393(0.1-10 \mu \mathrm{M})$ consistently suppressed whole-cell, tetrodotoxin-sensitive $\mathrm{Na}^{+}$current in $\sim 80 \%$ of the neurons we tested (Figs. 2, 8). This effect was completely prevented by the D1 receptor antagonist $\mathrm{SCH}$ $23390(1 \mu \mathrm{M})$ (Fig. 2) but not by the D2 receptor-selective antagonist eticlopride ( $1 \mu \mathrm{M} ; n=3$; not shown). The inhibitory modulation was produced through the classic D1 receptor transduction pathway involving activation of $G_{s}$ protein, stimulation of adenylyl cyclase activity, formation of cAMP, and dissociation of regulatory and catalytic subunits of cAMPdependent protein kinase (PKA), leading to phosphorylation of VSSCs. Thus, the SKF 38393-induced suppression of whole-

\section{A. 8-Br-cAMP}

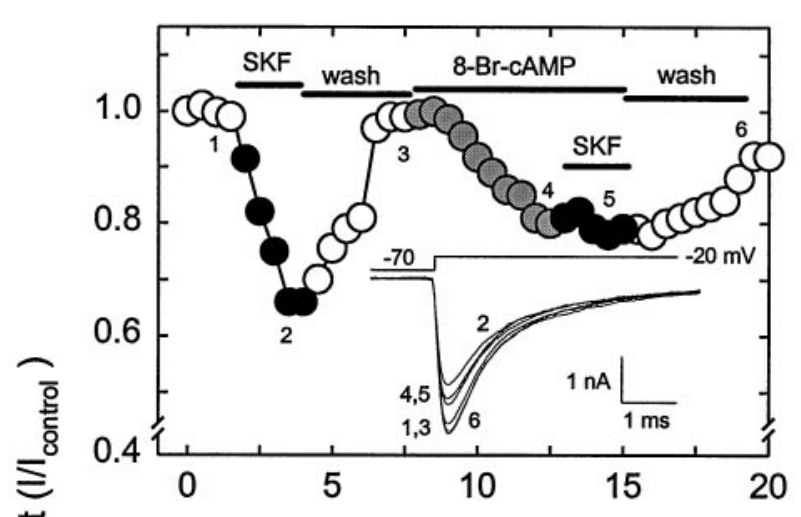

B. GDP- $\beta-S$

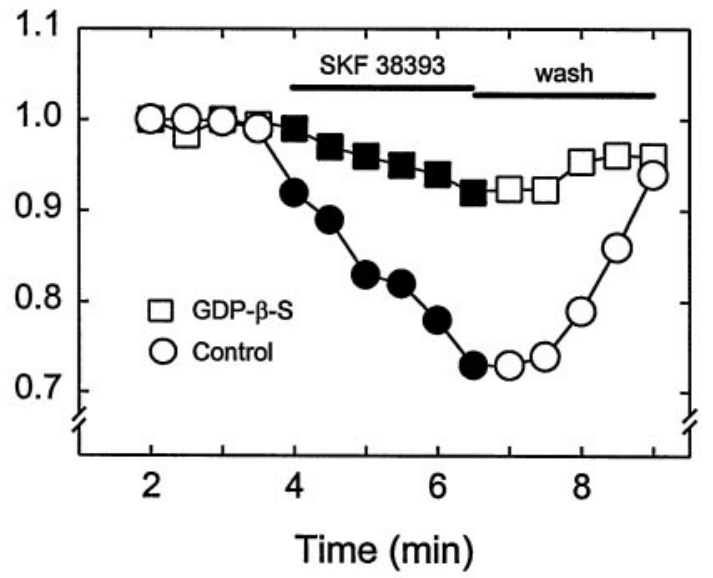

Figure 3. The D1 agonist-induced suppression of $\mathrm{Na}^{+}$current involves $\mathrm{G}_{\mathrm{s}}$ protein activation of cAMP. $A$, This combination of time plot and current traces (inset) shows that the suppression produced by SKF 38393 was mimicked by the membrane-permeable cAMP analog 8-Br-cAMP (50 $\mu \mathrm{M} ; n=6 ; 37.3 \pm 10.6 \%$ suppression), which also occluded the effect of SKF 38393. $B$, These time-response curves compare the suppression of $\mathrm{Na}^{+}$currents by SKF 38393 in a control neuron and a neuron that had been dialyzed with the nonhydrolyzable GDP analog $G D P-\beta-S$, which prevents activation of $G_{s}$ proteins. Note the marked reduction in the efficacy of SKF 38393 (2.8 $\pm 1.4 \%$ suppression; $n=7)$.

cell $\mathrm{Na}^{+}$conductance was mimicked by bath application of the membrane-permeable cAMP analog 8-bromo-cAMP $(50 \mu \mathrm{M})$, which also occluded the inhibition produced by SKF 38393, demonstrating that the agonist effect was mediated by increased cAMP formation (Fig. $3 A$ ). Similar suppression of $\mathrm{Na}^{+}$currents was observed after intracellular dialysis (via the patch-clamp electrode) with the catalytic subunit of PKA (Fig. $4 A$ ), which also precluded SKF 38393-induced inhibition. In addition, the modulation observed with the D1 receptorselective agonist was prevented by intracellular dialysis with either an inhibitor of PKA, PKI [5-24] (Fig. 4B), or an inhibitor of $\mathrm{G}_{\mathrm{s}}$ activation, the nonhydrolyzable GDP analog guanosine 5'-0-(2-thiodiphosphate) (GDP- $\beta-S$, Fig. $3 B)$. The voltage dependence of both activation and inactivation were unchanged (Fig. 5). This profile of effects is consistent with PKA phosphorylation of brain type IIA sodium channel $\alpha$-subunits (Gershon et al., 1992; Li et al., 1992). 
A. PKA

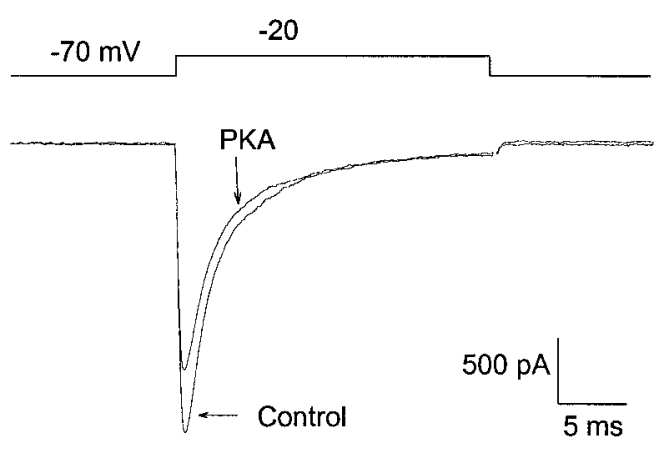

\section{B. PKI + SKF 38393}

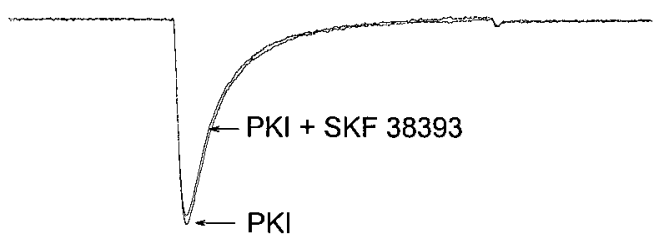

Figure 4. The D1 agonist-induced suppression of $\mathrm{Na}^{+}$currents involves cyclic-AMP-dependent protein kinase $(P K A)$. $A$, The suppression of $\mathrm{Na}^{+}$ current by D1 agonists was mimicked by the catalytic subunit of PKA $(50-100 \mathrm{U} / \mathrm{ml} ; n=8)$, which was dialyzed into the neurons through the patch pipette. $\mathrm{Na}^{+}$current reduction was observed 4 min after membrane seal rupture. $B$, The PKA inhibitor PKI [5-24] $(10 \mu \mathrm{M})$ prevented the suppression of $\mathrm{Na}^{+}$current by SKF 38393 after 4 min of dialysis into the neuron $(n=9)$.

\section{$\mathrm{Na}^{+}$current density is reduced in cocaine-pretreated NAc neurons}

Having characterized the DA receptor modulation of VSSCs in NAc neurons, we next examined whether $\mathrm{Na}^{+}$conductance was altered by repeated cocaine administration. In NAc neurons obtained from cocaine-pretreated rats, peak whole-cell $\mathrm{Na}^{+}$current density (current/capacitance) was greatly reduced $(37 \%)$ compared with that of saline-pretreated control neurons (Fig. $6 A$ ). This effect was clearly caused by a reduction in current, because cell capacitance was not significantly different ( $t$ test) in the two groups of neurons: saline, $6.1 \pm 0.34$; cocaine, $6.3 \pm 0.37$. Reductions in peak $\mathrm{Na}^{+}$currents can result in reduced action potential amplitudes in medium spiny neurons (Fraser et al., 1993), as we observed in our current-clamp recordings. $I-V$ recordings (Fig. 6B,C) indicated that the reduction in $\mathrm{Na}^{+}$current was accompanied by a significant depolarizing shift of $5.2 \mathrm{mV}$ in the voltage-dependence of activation and a reduction in the slope of steady-state activation (Fig. $6 D$ ). The $+5.2 \mathrm{mV}$ shift in the voltage dependence of activation may be directly responsible for the $+5.8 \mathrm{mV}$ increase in firing threshold observed in brain slices. Indeed, mathematical modeling of $\mathrm{Na}^{+}$channel function indicates that $\mathrm{a}+2.2 \mathrm{mV}$ alteration in activation voltage produces a $+2.6 \mathrm{mV}$ shift in threshold (Halter et al., 1995). We found no significant alteration in the voltage-dependence of inactivation (Fig. 6E). As in our current-clamp recordings, repeated administration of the $\mathrm{Na}^{+}$channel blocker lidocaine failed to reproduce the alterations in whole-cell $\mathrm{Na}^{+}$currents observed after repeated cocaine (see Fig. 6 legend). Thus, the effects cannot be

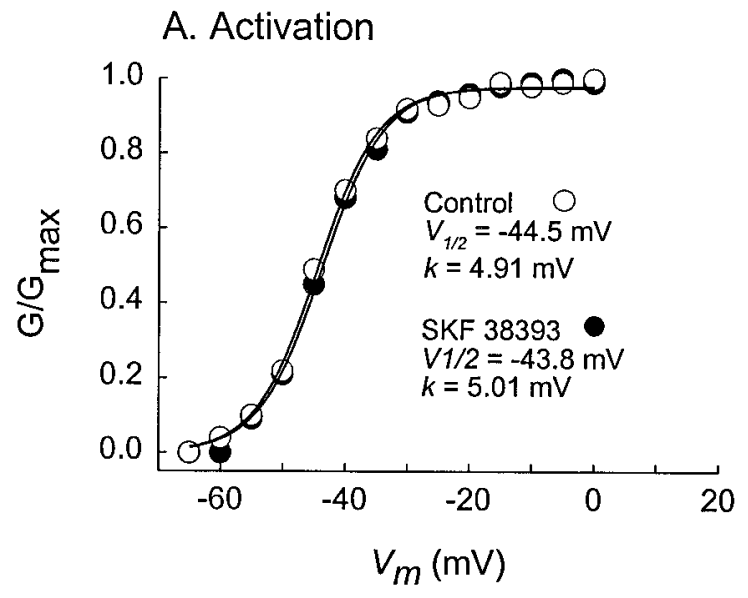

B. Inactivation

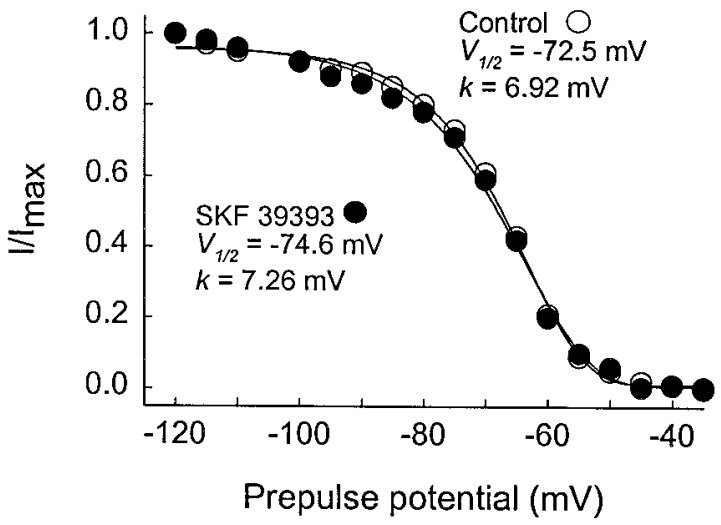

Figure 5. D1 agonist-induced suppression of $\mathrm{Na}^{+}$current occurred without alterations in the voltage dependence of activation or inactivation. $A$, The voltage-dependence of activation of whole-cell $\mathrm{Na}^{+}$current was not altered by SKF 38393. Relative conductance is plotted as a function of test potential. Activation curves were determined by voltageclamping cells at $-70 \mathrm{mV}$ and applying voltage steps to potentials of -70 to $+60 \mathrm{mV}$. To ensure that channel inactivation was removed completely, a lower frequency $(0.1-0.2 \mathrm{~Hz})$ was used. Peak currents were obtained at every test potential. Conductance was derived according to the equation $G_{\mathrm{Na}}=I_{\mathrm{Na} \text {,peak }} /\left(V-V_{\mathrm{Na}}\right)$, where $G_{\mathrm{Na}}$ is conductance, $I_{\mathrm{Na} \text {,peak }}$ is peak $\mathrm{Na}^{+}$ current, $V$ is test potential, and $V_{\mathrm{Na}}$ is the $\mathrm{Na}^{+}$reversal potential. The steady-state activation curves ( $m$-curve) were determined by plotting $G_{\mathrm{Na}} / G_{\mathrm{Na} \text {, max }}$ versus membrane potential as the Boltzmann equation $m=$ $\left[1+\exp \left(V-V_{1 / 2}\right) / k\right]-1$ where $V_{1 / 2}$ is the midpoint of the $m$-curves and $k$ is the curve slope factor. $B$, The voltage dependence of inactivation was not altered by SKF 38393. Relative current is plotted as a function of prepulse potential. Steady-state inactivation curves were determined with a conditioning prepulse protocol. Cells were voltage-clamped at $-70 \mathrm{mV}$. Membrane potential was first stepped (prepulse) to potentials from -120 to $-40 \mathrm{mV}$ (200 msec duration) before evoking $\mathrm{Na}^{+}$currents with a step to $-20 \mathrm{mV}$. The steady-state inactivation curves ( $h$-curves; $h=I_{\mathrm{Na}}$, peak $/ I_{\mathrm{Na} \text {,max }}$ vs conditioning potential) were fitted to a Boltzmann equation $h=\left[1+\exp \left(V-V_{1 / 2}\right) / k\right]-1$, where $V_{1 / 2}$ is the half-point of the inactivation curve and $k$ is the slope factor. Time constants for inactivation were obtained by fitting traces to a single exponential.

attributed to the local anesthetic properties of cocaine. In addition, recordings from acutely dissociated cortical neurons failed to reveal changes in VSSCs such as those seen in the NAc (Table 2), indicating that the effects do not reveal a general action on brain neurons but rather reflect the intrinsic properties of the neurons 
A.

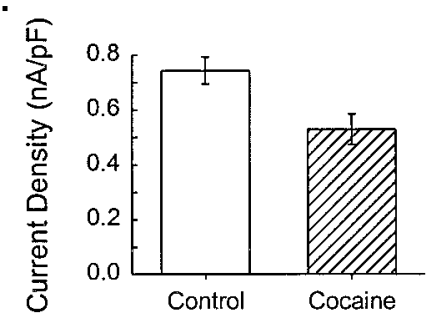

B.

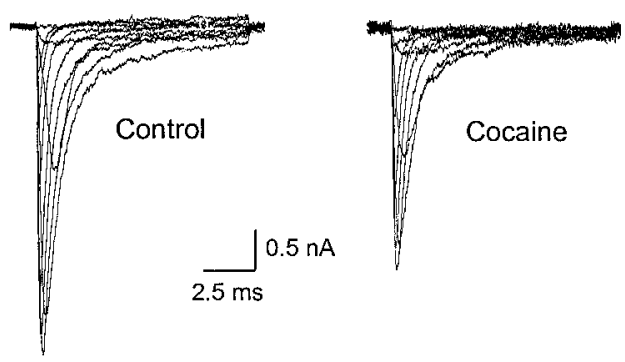

C.

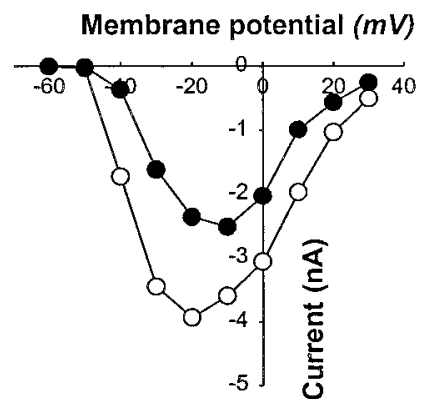

D.

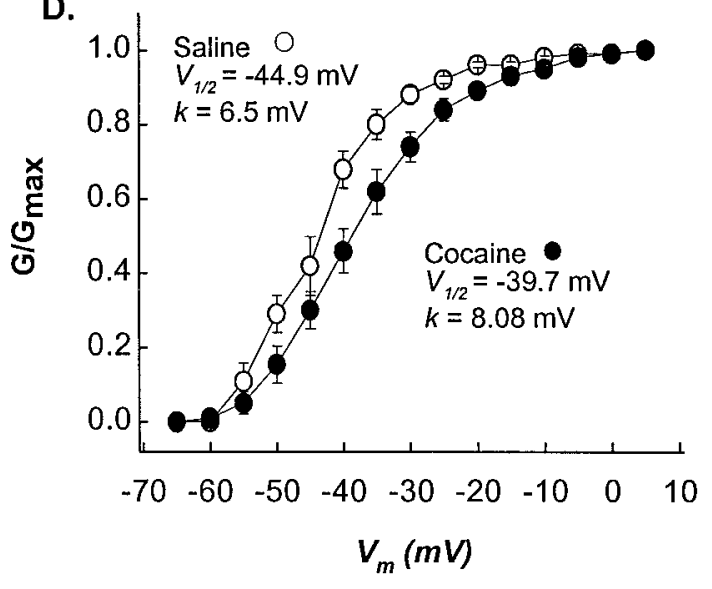

E.

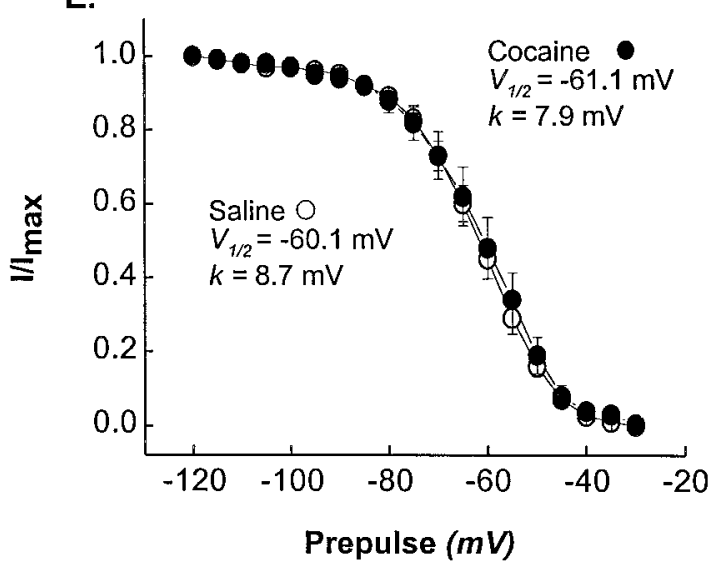

Figure 6. Repeated cocaine treatment reduced NAc Na ${ }^{+}$currents and caused a depolarizing shift in the voltage dependence of activation. $A$, NAc neurons $(n=33)$ from cocaine-pretreated rats exhibited significantly $\left(t_{68}=2.75 ; p=0.0075\right)$ reduced peak whole-cell $\mathrm{Na}^{+}$currents $(\mathrm{measured}$ at -20 $\mathrm{mV}$ ) as compared with neurons $(n=37)$ obtained from saline-pretreated rats. Results are presented as current density to normalize for capacitance (see Results). $B$, Recordings showing $I-V$ relationship for $\mathrm{Na}^{+}$currents in a control and a cocaine-pretreated NAc neuron. $C$, Plots of the $I-V$ curves for the two neurons shown in $B$. $D$, Cocaine pretreatment caused a depolarizing shift in the voltage dependence of activation and reduced the slope factor ( $k$ ). Values were obtained for each neuron at each membrane voltage, and the mean \pm SEM were plotted. Half-maximal activation $\left(V_{1 / 2}\right)$ and slope $(k)$ values were obtained individually for each neuron and compared with $t$ tests. Half-maximal activation occurred at significantly $\left(t_{28}=2.26 ; p=0.031\right)$ more depolarized potentials in cocaine-pretreated neurons $(-40.3 \pm 1.8 \mathrm{mV} ; n=16)$ as compared with saline-pretreated neurons $(46.1 \pm 1.2 ; n=14)$. The slope factor was also significantly decreased $\left(t_{28}=3.13 ; p=0.004\right)$ in the cocaine group $(8.85 \pm 0.8)$ as compared with the saline group $(4.01 \pm 0.8)$. Note that the $V_{1 / 2}$ and $k$ values shown in the figure were derived from the curves fitted to the mean values depicted in the figure, not from the mean values (given here) obtained by averaging all of the neurons in the sample. $E$, The voltage dependence of inactivation was not altered by repeated cocaine treatment. Values were obtained from the mean \pm SEM as in $B(n=16$ for cocaine; $n=13$ for saline). Note that repeated administration of lidocaine failed to produce effects similar to those of cocaine: $\mathrm{Na}^{+}$current density $=0.81 \pm 0.058, n=9$; activation $V_{1 / 2}=-42.4 \pm 1.8, k=5.2 \pm 0.8, n=8$; and inactivation $V_{1 / 2}=-60.6 \pm 2.5, k=7.0 \pm 0.4, n=9$. None of these values was significantly different from control $(t$ tests). See Figure 5 legend for details regarding activation and inactivation curves.

and the particular set of neurotransmitter inputs and receptors that are impacted by cocaine.

A possible mechanism for the reduction in peak $\mathrm{Na}^{+}$current density observed in cocaine-pretreated NAc neurons is increased phosphorylation. VSSCs contain several consensus sites for PKA phosphorylation and at least two for PKC phosphorylation. In both cases, phosphorylation leads to a decrease in $\mathrm{Na}^{+}$conductance (for review, see Catterall, 1992). However, the reduction in current produced by PKA phosphorylation is not accompanied by a depolarizing shift and a reduced slope of the voltage dependence of activation, as observed in our neurons. There are reports that PKC phosphorylation of rat brain IIA $\mathrm{Na}^{+}$channel $\alpha$-subunits expressed in Xenopus oocytes reduced peak $\mathrm{Na}^{+}$ current and caused a depolarizing shift in the voltage dependence of activation similar to that reported here (Dascal and Lotan, 1991). However, this effect was not seen by Catterall and colleagues, who reported reductions in peak current accompanied by a slowing of inactivation in both cultured rat brain neurons and Chinese hamster ovary cells expressing the IIA $\alpha$-subunit $(\mathrm{Nu}-$ mann et al., 1991). To determine how PKC phosphorylation of VSSCs alters conductance in rat NAc neurons, we tested the effects of the PKC activator phorbol 12-myristate 13-acetate (PMA). Bath application of PMA $(1 \mu \mathrm{M})$ produced variable reductions in $\mathrm{Na}^{+}$current $(18.7 \pm 2.0 \%)$, with no alterations in the voltage dependence of activation or inactivation (Fig. 7). In approximately half of the neurons tested, we observed a slight 
Table 2. Repeated cocaine administration did not alter whole-cell $\mathrm{Na}^{+}$ current in freshly dissociated cortical neurons

\begin{tabular}{lcc} 
& Control $(n=9)$ & Cocaine $(n=8)$ \\
\hline $\mathrm{Na}^{+}$current density $(\mathrm{nA} / \mathrm{pF})$ & $0.35 \pm 0.03$ & $0.34 \pm 0.03$ \\
Half-maximal activation $(\mathrm{mV})$ & $-34.8 \pm 1.0$ & $-36.9 \pm 1.0$ \\
Activation slope $(\mathrm{mV})$ & $5.2 \pm 0.6$ & $4.9 \pm 0.7$ \\
Half-maximal inactivation $(\mathrm{mV})$ & $-61.8 \pm 1.7$ & $-62.8 \pm 2.4$ \\
Inactivation slope $(\mathrm{mV})$ & $6.5 \pm 0.5$ & $6.4 \pm 0.6$
\end{tabular}

slowing of inactivation (Fig. 7). These results suggest that the depolarizing shift in the voltage dependence of activation is unlikely to have resulted from enhanced PKC phosphorylation.

\section{D1 receptor suppression of $\mathrm{Na}^{+}$currents in NAC neurons is not altered by cocaine pretreatment}

Our previous in vivo work has suggested that D1 receptormediated suppression of NAc neuronal activity was enhanced in cocaine-pretreated rats (see introductory remarks). Therefore, we next compared the ability of SKF $38393(0.1-10 \mu \mathrm{M})$ to suppress $\mathrm{Na}^{+}$conductance in NAc neurons dissociated from cocaine- and saline-pretreated rats. To our surprise, the suppres- sion of $\mathrm{Na}^{+}$current by SKF 38393 was nearly identical in the two sets of neurons (Fig. 8), indicating that there was no D1 receptor supersensitivity in the cocaine-pretreated NAc neurons using this measure. This finding suggests that PKA phosphorylation of VSSCs is not maximal after repeated cocaine administration, given that D1 receptor stimulation can further suppress $\mathrm{Na}^{+}$ conductance. Despite the similar suppression of $\mathrm{Na}^{+}$conductance produced by D1 receptor stimulation in the two groups of neurons, the in vivo effect in cocaine-pretreated rats would be a further reduction in $\mathrm{Na}^{+}$conductance caused by the decreased basal state of conductance produced by cocaine pretreatment.

\section{DISCUSSION}

Repeated administration of cocaine causes many adaptations within neural systems, from alterations in transporters, receptors, and transduction molecules to changes in gene expression (for review, see Hammer, 1995). The present results demonstrate a new adaptation: reductions in the basal functioning of VSSCs in NAc neurons. Our previous in vivo recordings demonstrated that NAc neurons were less responsive to the excitatory effects of locally applied glutamate (White et al., 1995b), but the present results indicate a more global reduction in excitability because VSSCs are responsible for action potential
A.

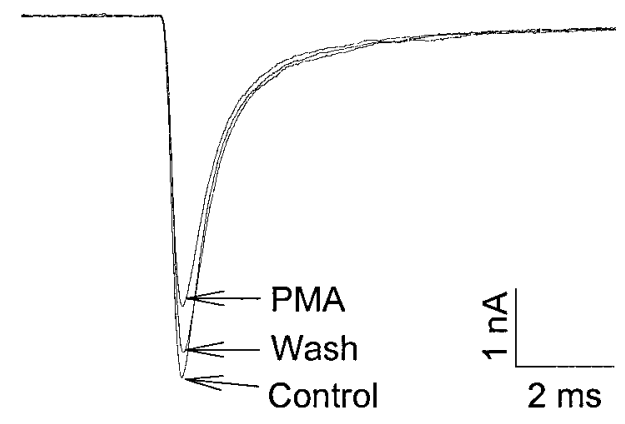

B.

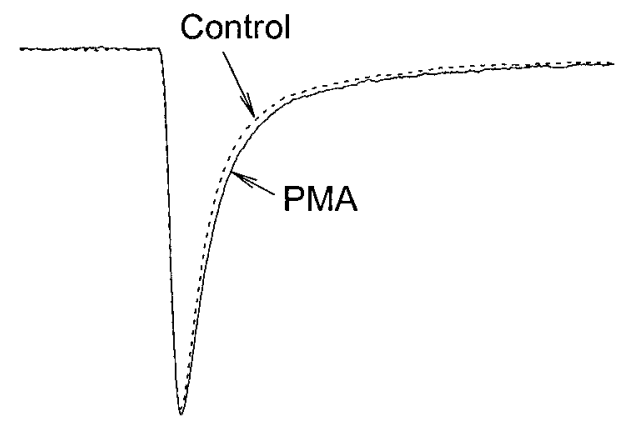

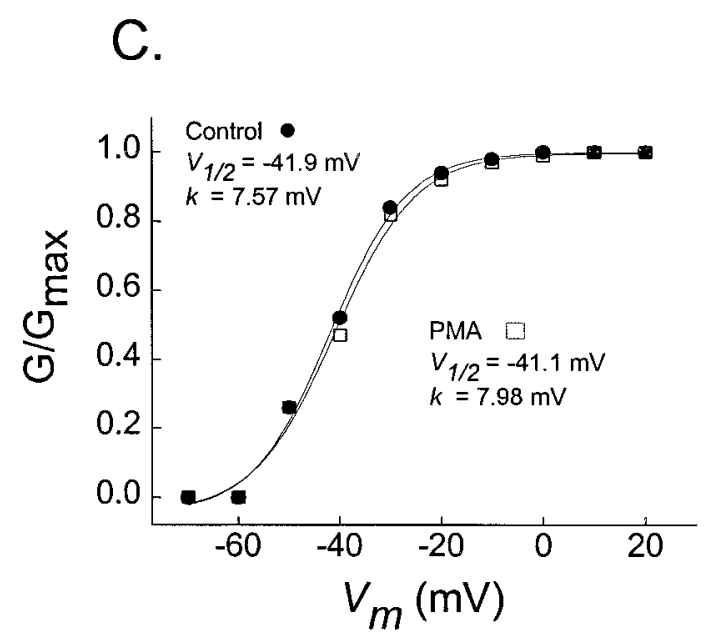

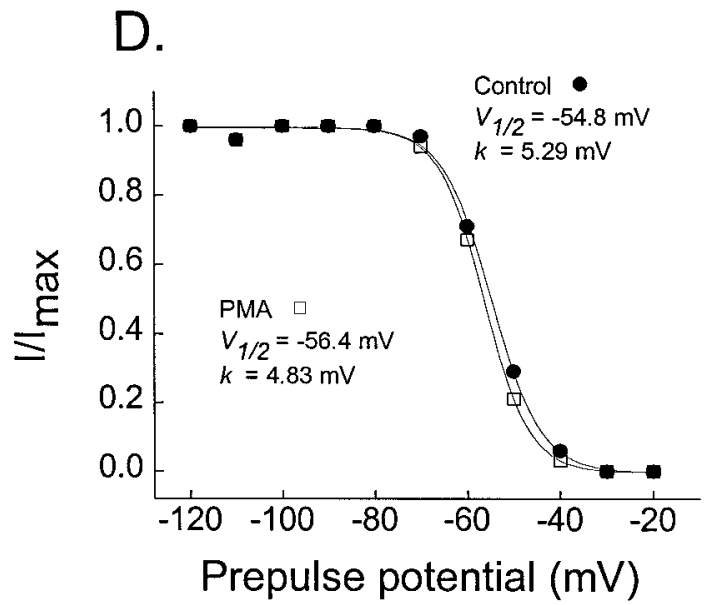

Figure 7. Phosphorylation of sodium channels by PKC decreased whole-cell Na ${ }^{+}$current and slightly delayed inactivation. $A$, Administration of the PKC activator PMA $(1 \mu \mathrm{M})$ decreased peak $\mathrm{Na}^{+}$current. $B$, The traces in $A$ have been rescaled such that current amplitude is normalized in the two conditions. This allows better detection of the slower inactivation in the presence of PMA. However, this effect was observed in only four of nine neurons. $C$, The voltage dependence of activation was not altered by PMA treatment $(n=3)$. $D$, The voltage dependence of inactivation was not altered by PMA treatment $(n=3)$. See Figure 5 legend for details of activation and inactivation curves. 


\section{D1 Receptor Sensitivity}

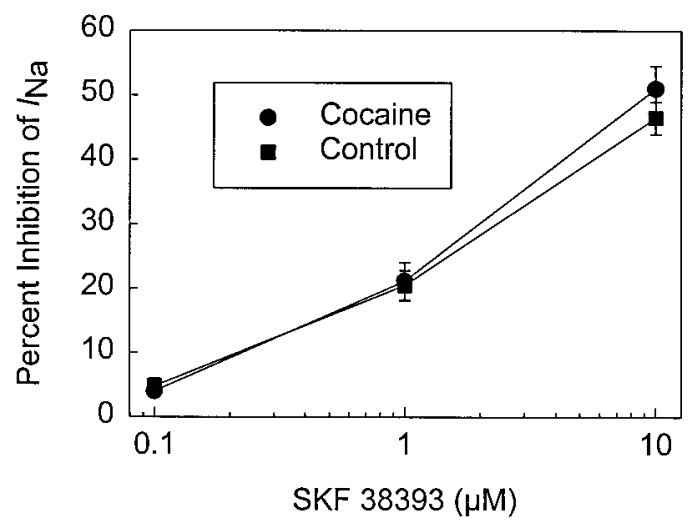

Figure 8. D1 agonist-induced suppression of whole-cell $\mathrm{Na}^{+}$current in NAc neurons is not altered by repeated cocaine administration. The ability of the DA D1 receptor-selective agonist SKF $38393(0.1-10 \mu \mathrm{M})$ to suppress whole-cell $\mathrm{Na}^{+}$current was not significantly different (ANOVA) in NAc neurons recorded from cocaine-treated rats and saline-treated control rats. Sample sizes for the 0.1, 1.0, and $10.0 \mu \mathrm{M}$ concentrations of SKF 38393 are 6, 6, and 5 for both control and cocaine groups. In addition, another group of 30 cocaine pretreated neurons were tested with $1.0 \mu \mathrm{M}$ SKF 38393 and exhibited average inhibition of $27.2 \pm 1.7 \%$, a value that is not significantly different from that obtained in 33 untreated neurons $(24.5 \pm 2.1 \%)$, as described in Figure 2 legend $(t$ test).

generation. The effect of chronic cocaine cannot be attributed to direct effects on VSSCs because during in vivo administration our dose regimen produces brain concentrations of cocaine $(<3 \mu \mathrm{M})$ (Pettit et al., 1990) that are considerably less than those $(25-50 \mu \mathrm{M})$ needed to interact with VSSCs and to alter membrane potential (Reith et al., 1986; Zimanyi et al., 1989; Wheeler et al., 1993). In addition, repeated administration of the local anesthetic lidocaine, which blocks VSSCs but does not exert actions on monoamine transporters, failed to mimic the effects of cocaine both in our brain slice and in dissociated neuron preparations. Moreover, recordings from acutely dissociated cortical neurons failed to reveal changes in VSSCs such as those seen in the NAc, indicating that the effects do not reveal a general action on brain neurons but reflect instead the specific set of monoamine and other receptors and signaling pathways that are expressed by NAc neurons and impacted by the ability of cocaine to increase synaptic concentrations of dopamine and other neurotransmitters. We propose that by increasing synaptic levels of DA and other neurotransmitters within the NAc, cocaine causes compensatory alterations in signaling pathways that regulate excitability of NAc neurons and thereby renders the NAc considerably less responsive to excitatory commands.

\section{Repeated cocaine administration alters membrane properties of NAc neurons}

During cocaine withdrawal, NAc neurons exhibited a number of alterations in membrane properties, including hyperpolarized membrane potentials, increased action potential thresholds, increased rheobase, and decreased action potential amplitude, effects that were not caused by cocaine during the recordings because our experiments were conducted $3 \mathrm{~d}$ after the last cocaine injection. Although these changes are not related to direct effects of cocaine on VSSCs, they do indicate that repeated cocaine causes adaptations in voltage-dependent conductances that control neuronal excitability. The resting membrane poten- tial of NAc neurons is primarily determined by an inward rectifying $\mathrm{K}^{+}\left(\mathrm{K}_{\mathrm{IR}}\right)$ channel (Uchimura et al., 1989). Within medium spiny neurons of the NAc, $\mathrm{K}_{\mathrm{IR}}$ is known to be modulated by DA receptors (Uchimura and North, 1990). Given that D1 receptors hyperpolarize NAc neurons by opening $\mathrm{K}_{\mathrm{IR}}$ (Uchimura et al., 1989; Uchimura and North, 1990) and that the D1 receptor signaling pathway is upregulated by repeated cocaine administration (Self and Nestler, 1995), it seems likely that the more hyperpolarized resting membrane potentials resulted from enhanced $\mathrm{K}_{\mathrm{IR}}$ conductance in the cocaine-pretreated NAc neurons. Possible changes in this and other $\mathrm{K}^{+}$channels are being pursued in additional experiments. The remainder of the present study focused on VSSC modulation because the set of additional alterations in $\mathrm{Na}^{+}$spike characteristics (rheobase, threshold, amplitude) is most suggestive of $\mathrm{Na}^{+}$current changes (Halter et al., 1995).

\section{Reduced excitability of NAc neurons by repeated cocaine treatment results from decrements in whole- cell $\mathrm{Na}^{+}$currents}

Our whole-cell recordings indicate that, as in the neighboring dorsal striatum (Surmeier et al., 1992; Cepeda et al., 1995; Schiffmann et al., 1995), $\mathrm{Na}^{+}$conductance in medium spiny NAc neurons is consistently reduced by DA D1 receptor stimulation through activation of the CAMP-PKA pathway and phosphorylation of VSSCs. In addition, our findings indicate that repeated cocaine treatment markedly reduced $(37 \%)$ the basal peak $\mathrm{Na}^{+}$ current while it shifted the voltage dependence of activation in the depolarizing direction. These changes would explain the increased rheobase, increased spike threshold, and reduced spike amplitude observed in our slice recordings. The reduction in whole-cell $\mathrm{Na}^{+}$conductance could be attributed to reduction in single-channel current, the number of active $\mathrm{Na}^{+}$channels, or the open probability of the channels during depolarization. Although single-channel recordings will be required to distinguish between these possibilities, there are several findings that lead us to believe that the responsible mechanism may be a reduction in open probability. Enhanced phosphorylation of VSSCs by cAMPdependent protein kinase reduces whole-cell $\mathrm{Na}^{+}$current by decreasing channel open probability (Gershon et al., 1992; Li et al., 1992). The cAMP-PKA pathway in the NAc is clearly upregulated by repeated cocaine treatment, with increases in levels of both cAMP and PKA (Terwilliger et al., 1991). Because the activity of VSSCs is dynamically regulated by fluctuations in cAMP and PKA concentrations (Catterall, 1992), the basal state of VSSC phosphorylation may be enhanced in NAc neurons recorded from rats after repeated cocaine treatment. Prolonged substrate phosphorylation produced by repeated psychomotor stimulant administration has several precedents, including tyrosine hydroxylase and extracellular signal-related kinase (ERK) in the VTA (Beitner-Johnson and Nestler, 1991; Berhow et al., 1996) and cAMP response element-binding protein (CREB) in the NAc (Cole et al., 1995; Fitzgerald and Nestler, 1995). How does the upregulation of the cAMP-PKA pathway come about? A likely candidate is the relatively persistent decrease in NAc levels of $G_{i}$ and $G_{o}$ proteins produced by repeated cocaine administration (Nestler et al., 1990; Terwilliger et al., 1991; Striplin and Kalivas, 1993). Because these proteins couple many receptors to inhibition of adenylyl cyclase, the decreased functional activity in this opposing system would lead to increased cAMP and PKA concentrations.

The second alteration in $\mathrm{Na}^{+}$conductance that we observed in 
cocaine-pretreated NAc neurons was a depolarizing shift and a reduced slope of the voltage dependence of activation. These effects are not associated with enhanced PKA phosphorylation of VSSCs (Catterall, 1992). They also could not be attributed to PKC phosphorylation, as suggested by experiments in which PKC was used to phosphorylate $\mathrm{Na}^{+}$channels expressed in Xenopus oocytes (Dascal and Lotan, 1991), because phorbol ester administration to our neurons reduced whole-cell $\mathrm{Na}^{+}$current without modifying the voltage dependence of activation or inactivation. So, what caused the depolarizing shift in the voltage dependence of activation in our cocaine-pretreated neurons? One possible mechanism would be a reduction in direct G-protein modulation of VSSCs (Ma et al., 1994), which may also result from the reduction in levels of these proteins caused by repeated cocaine treatment (Nestler et al., 1990; Terwilliger et al., 1991; Striplin and Kalivas, 1993).

\section{D1 receptor modulation of $\mathrm{Na}^{+}$conductance is normal in cocaine-withdrawn NAc neurons}

Although our earlier in vivo recordings have consistently indicated that repeated cocaine administration causes a persistent enhancement in the ability of D1 receptor stimulation to suppress the firing of NAc neurons (Henry et al., 1989; Henry and White, 1991,1995), the suppression of whole-cell $\mathrm{Na}^{+}$current by D1 receptor stimulation was normal in cocaine-pretreated neurons. The lack of an enhanced D1 receptor-mediated response is also consistent with many reports that D1 receptors are unaltered by repeated cocaine treatment using standard intermittent injection procedures (for review, see Self and Nestler, 1995). Thus, the apparent supersensitivity of D1 receptor-mediated inhibitory responses has been attributed to alterations in the cAMP transduction cascade (Self and Nestler, 1995; White et al., 1995a). Our new findings implicate the decreased excitability of NAc neurons in the apparent D1 receptor supersensitivity.

In the anesthetized preparation used in our earlier in vivo recordings, most NAc neurons were quiescent and thus were induced to fire by iontophoretic application of glutamate. A reduction in excitability by downregulation of $\mathrm{Na}^{+}$conductance would explain the reduced ability of glutamate to drive the NAc neurons in cocaine-pretreated rats (White et al., 1995b), an effect that cannot be explained by alterations in NAc glutamate receptor subunit expression during the early days of withdrawal from repeated cocaine administration (Fitzgerald et al., 1996). The reduction in $\mathrm{Na}^{+}$conductance would make D1 receptor stimulation appear more effective at producing inhibition because the effect has to be measured against glutamate-induced activity. Because the efficacy of glutamate is reduced, there exists a bias toward inhibitory efficacy, which would explain why NAc neurons also appear more sensitive to other inhibitory agents such as GABA and serotonin (Henry and White, 1991; White et al., 1992). Time course studies indicate that the enhanced inhibitory efficacies of GABA and serotonin, unlike that of D1 receptor agonists, are quite transient (White et al., 1995a). If these transient alterations are a reflection of reduced $\mathrm{Na}^{+}$conductance, then it may be that the latter effect is also transient and that the apparent in vivo D1 receptor supersensitivity observed at later withdrawal times (weeks) reflects alterations that are more specific to that receptor system.

\section{Functional implications of whole-cell plasticity for cocaine withdrawal}

Our studies have demonstrated a novel form of whole-cell (nonsynaptic) plasticity produced by repeated cocaine administration: reduced $\mathrm{Na}^{+}$currents in NAc neurons. Although it is certain that cocaine-induced alterations in transmission at specific synapses will modify the responsiveness of NAc neurons to selected inputs (synaptic plasticity), as demonstrated previously in the VTA (Bonci and Williams, 1996) and dorsal lateral septal nucleus (Shoji et al., 1997), the reduction of VSSC function will produce an indiscriminate decrease in the responsiveness of the NAc to excitatory commands because these channels govern the initiation of action potentials. In addition, reduced $\mathrm{Na}^{+}$conductance could also impact associative synaptic plasticity because VSSCs expressed within neuronal soma and dendrites carry backpropagating action potentials that modulate dendritic $\mathrm{Ca}^{2+}$ influx (Johnston et al., 1996; Stuart et al., 1997).

The NAc is a structure in which functionally distinct ensembles of neurons are recruited by convergent excitatory inputs to coordinate patterns of movement and affect (for review, see Pennartz et al., 1994). Given that major excitatory inputs to NAc originate within structures known to be involved in motivated behavior and the learned associations between such behavior and both specific environmental settings and emotional states (prefrontal cortex, hippocampus, and basolateral amygdala), a reduction in the excitability of NAc neurons would decrease processing of such information and could thereby lead to cocaine withdrawal effects such as anergia, anhedonia, and depression. In rat models, such deficits are observed during the early days of withdrawal from repeated cocaine administration (Markou and Koob, 1991; Koeltzow et al., 1996), when $\mathrm{Na}^{+}$currents are depressed. Accordingly, the further reduction in $\mathrm{Na}^{+}$currents after D1 receptor agonist administration suggests that the proposed use of such drugs as a replacement therapy for cocaine-dependent individuals (Self et al., 1996) may be contraindicated during the early period of cocaine withdrawal.

\section{REFERENCES}

Baxter DA, Bittner GD (1981) Intracellular recordings from crustacean motor axons during presynaptic inhibition. Brain Res 223:422-428.

Beitner-Johnson D, Nestler EJ (1991) Morphine and cocaine exert common chronic action on tyrosine hydroxylase in dopaminergic brain regions. J Neurochem 57:344-347.

Berhow MT, Hiroi N, Nestler EJ (1996) Regulation of ERK (extracellular signal regulated kinase), part of the neurotrophin signal transduction cascade, in the rat mesolimbic dopamine system by chronic exposure to morphine or cocaine. J Neurosci 16:4707-4715.

Bonci A, Williams JT (1996) A common mechanism mediates long-term changes in synaptic transmission after chronic cocaine and morphine. Neuron 16:631-639.

Catterall WA (1992) Cellular and molecular biology of voltage-gated sodium channels. Physiol Rev 72:S15-S48.

Cepeda C, Chandler SH, Shumate LW, Levine MS (1995) Persistent $\mathrm{Na}^{+}$conductance in medium-sized neostriatal neurons: characterization using infrared videomicroscopy and whole cell patch-clamp recordings. J Neurophysiol 74:1343-1348.

Charlton MP, Bittner GD (1978) Presynaptic potentials and facilitation of transmitter release in the squid giant axon. J Gen Physiol 72:487-511.

Colatsky TJ, Tsien RW (1979) Sodium channels in rabbit cardiac Purkinje fibres. Nature 278:265-268.

Cole RL, Konradi C, Douglass J, Hyman SE (1995) Neuronal adaptation to amphetamine and dopamine: molecular mechanisms of prodynorphin gene regulation in rat striatum. Neuron 14:813-823.

Cornish JW, O'Brien CP (1996) Crack cocaine abuse: an epidemic with many public health consequences. Annu Rev Public Health 17:259-273.

Dascal N, Lotan I (1991) Activation of protein kinase C alters voltage dependence of a Na${ }^{+}$channel. Neuron 6:165-175.

Fitzgerald LW, Nestler EJ (1995) Cocaine regulation of signal transduction pathways. In: The neurobiology of cocaine: cellular and molecular mechanisms (Hammer Jr RP, ed), pp 225-246. Boca Raton: CRC. 
Fitzgerald LW, Ortiz J, Hamedani AG, Nestler EJ (1996) Drugs of abuse and stress increase the expression of GluR1 and NMDAR1 glutamate receptor subunits in the rat ventral tegmental area: common adaptations among cross-sensitizing agents. J Neurosci 16:274-282.

Fraser DD, Hoehn K, Weiss S, MacVicar BA (1993) Arachidonic acid inhibits sodium currents and synaptic transmission in cultured striatal neurons. Neuron 11:633-644.

Galloway MP (1992) Neuropharmacology of cocaine: effects on dopamine and serotonin systems. In: Cocaine: pharmacology, physiology and clinical strategies (Lakoski JM, Galloway MP, White FJ, eds), pp 163-189. Boca Raton: CRC.

Gawin FH (1991) Cocaine addiction: psychology and neurophysiology. Science 251:1580-1586.

Gershon E, Weigl L, Lotan I, Schreibmayer W, Dascal N (1992) Protein kinase A reduces voltage-dependent $\mathrm{Na}^{+}$current in Xenopus oocytes. J Neurosci 12:3743-3752.

Halter JA, Carp JS, Wolpaw JR (1995) Operantly conditioned motoneuron plasticity: possible role of sodium channels. J Neurophysiol 73:867-871.

Hammer Jr RP (1995) The neurobiology of cocaine: cellular and molecular mechanisms. Boca Raton: CRC.

Henry DJ, White FJ (1991) Repeated cocaine administration causes persistent enhancement of D1 dopamine receptor sensitivity within the rat nucleus accumbens. J Pharmacol Exp Ther 258:882-890.

Henry DJ, White FJ (1995) The persistence of behavioral sensitization to cocaine parallels enhanced inhibition of nucleus accumbens neurons. J Neurosci 15:6287-6299.

Henry DJ, Greene MA, White FJ (1989) Electrophysiological effects of cocaine in the mesoaccumbens dopamine system: repeated administration. J Pharmacol Exp Ther 251:833-839.

Hyman SE (1996) Addiction to cocaine and amphetamine. Neuron 16:901-904.

Johnston D, Magee JC, Colbert CM, Christie BR (1996) Active properties of neuronal dendrites. Annu Rev Neurosci 19:165-186.

Kalivas PW, Duffy P (1993) Time course of extracellular dopamine and behavioral sensitization to cocaine. I. Dopamine axon terminals. J Neurosci 13:266-275.

Kleber HD (1995) Pharmacotherapy, current and potential, for the treatment of cocaine dependence. Clin Neuropharmacol 18[Suppl]1:S96-S109.

Koeltzow TE, Cooper DC, Vartanian AJ, White FJ (1996) Electrophysiological and behavioral characterization of an animal model of cocaine withdrawal. Soc Neurosci Abstr 22:926.

Koob GF, Bloom FE (1988) Cellular and molecular mechanisms of drug dependence. Science 242:715-723.

Koob GF (1992) Drugs of abuse: anatomy, pharmacology and function of reward pathways. Trends Pharmacol Sci 13:177-184.

Kuhar MJ, Pilotte NS (1996) Neurochemical changes in cocaine withdrawal. Trends Pharmacol Sci 17:260-264.

Li M, West JW, Lai Y, Scheuer T, Catterall WA (1992) Functional modulation of brain sodium channels by cAMP-dependent phosphorylation. Neuron 8:1151-1159.

Ma JY, Li M, Catterall WA, Scheuer T (1994) Modulation of brain $\mathrm{Na}^{+}$ channels by a G-protein-coupled pathway. Proc Natl Acad Sci USA 91:12351-12355.

Markou A, Koob GF (1991) Postcocaine anhedonia: an animal model of cocaine withdrawal. Neuropsychopharmacology 4:17-26.

Nestler EJ, Terwilliger RZ, Walker JR, Sevarino KA, Duman RS (1990) Chronic cocaine treatment decreases levels of the $G$ protein subunits $G_{\mathrm{i} \alpha}$ and $G_{\mathrm{o} \alpha}$ in discrete regions of rat brain. J Neurochem 55:1079-1082.

Nisenbaum ES, Xu ZC, Wilson CJ (1994) Contribution of a slowly inactivating potassium current to the transition to firing of neostriatal spiny projection neurons. J Neurophysiol 71:1174-1189.

Numann R, Catterall WA, Scheuer T (1991) Functional modulation of brain sodium channels by protein kinase $\mathrm{C}$ phosphorylation. Science 254:115-118.

O'Donnell P, Grace AA (1993) Physiological and morphological properties of accumbens core and shell neurons recorded in vitro. Synapse 13:135-160

O’Donnell P, Grace AA (1995) Synaptic interactions among excitatory afferents to nucleus accumbens neurons: hippocampal gating of prefrontal cortical input. J Neurosci 15:3622-3639.

O'Donnell P, Grace AA (1996) Dopaminergic reduction of excitability in nucleus accumbens neurons recorded in vitro. Neuropsychopharmacology 15:87-97.

Pennartz CMA, Groenewegen HJ, Lopes da Silva FH (1994) The nucleus accumbens as a complex of functionally distinct neuronal ensembles: an integration of behavioural, electrophysiological and anatomical data. Prog Neurobiol 42:719-761.

Pettit HO, Pan H-T, Parsons LH, Justice Jr JB (1990) Extracellular concentrations of cocaine and dopamine are enhanced during chronic cocaine administration. J Neurochem 55:798-804.

Postma SW, Catterall WA (1984) Inhibition of binding of $\left[{ }^{3} \mathrm{H}\right]$ batrachotoxin A $20-\alpha$-benzoate to sodium channels by local anesthetics. Mol Pharmacol 25:219-227.

Reith MEA (1992) Central and peripheral cocaine binding sites. In: Cocaine: pharmacology, physiology and clinical strategies (Lakoski JM, Galloway MP, White FJ, eds), pp 203-227. Boca Raton: CRC.

Reith MEA, Kim SS, Lajtha A (1986) Structural requirements for cocaine congeners to interact with $\left[{ }^{3} \mathrm{H}\right]$ batrachotoxinin A 20 - $\alpha$-benzoate binding sites on sodium channels in mouse brain synaptosomes. J Biol Chem 261:7300-7305.

Ritz MC, Lamb RJ, Goldberg SR, Kuhar MJ (1987) Cocaine receptors on dopamine transporters are related to self-administration of cocaine. Science 237:1219-1223.

Schiffmann SN, Lledo P-M, Vincent J-D (1995) Dopamine $\mathrm{D}_{1}$ receptor modulates the voltage-gated sodium current in rat striatal neurones through a protein kinase A. J Physiol (Lond) 483:95-107.

Self DW, Nestler EJ (1995) Molecular mechanisms of drug reinforcement and addiction. Annu Rev Neurosci 18:463-495.

Self DW, Barnhart WJ, Lehman DA, Nestler EJ (1996) Opposite modulation of cocaine-seeking behavior by $\mathrm{D}_{1^{-}}$and $\mathrm{D}_{2}$-like dopamine receptor agonists. Science 271:1586-1589.

Shoji S, Simms D, McDaniel WC, Gallagher JP (1997) Chronic cocaine enhances gamma-aminobutyric acid and glutamate release by altering presynaptic and not postsynaptic gamma-aminobutyric acid $_{B}$ receptors within the rat dorsolateral septal nucleus. J Pharmacol Exp Ther 280:129-137.

Simms D, Gallagher JP (1996) Modification of serotonin responses in rat dorsolateral septal nucleus neurons by acute and chronic cocaine. J Pharmacol Exp Ther 276:1292-1303.

Striplin CD, Kalivas PW (1993) Robustness of G protein changes in cocaine sensitization shown with immunoblotting. Synapse 14:10-15.

Stuart G, Spruston N, Sakman B, Häusser M (1997) Action potential initiation and backpropagation in neurons of the mammalian CNS. Trends Neurosci 20:125-131.

Surmeier DJ, Eberwine J, Wilson CJ, Cao Y, Stefani A, Kitai ST (1992) Dopamine receptor subtypes colocalize in rat striatonigral neurons. Proc Natl Acad Sci USA 89:10178-10182.

Terwilliger R, Beitner-Johnson D, Sevarino KA, Crain SM, Nestler EJ (1991) A general role for adaptations in G-proteins and the cyclic AMP system in mediating the chronic actions of morphine and cocaine on neuronal function. Brain Res 548:100-110.

Uchimura N, North RA (1990) Actions of cocaine on rat nucleus accumbens neurons in vitro. Br J Pharmacol 99:736-740.

Uchimura N, Higashi H, Nishi S (1986) Hyperpolarizing and depolarizing actions of dopamine via D-1 and D-2 receptors on nucleus accumbens neurons. Brain Res 375:368-372.

Uchimura N, Cherubini E, North RA (1989) Inward rectification in rat nucleus accumbens neurons. J Neurophysiol 62:1280-1286.

Volkow N, Fowler JS (1995) Brain imaging studies of the cocaine addict: implications for reinforcement and addiction. In: The neurobiology of cocaine: cellular and molecular mechanisms (Hammer Jr RP, ed), pp 65-78. Boca Raton: CRC.

Wang GK, Wang SS (1992) Altered stereoselectivity of cocaine and bupivacaine isomers in normal and batrachotoxin-modified $\mathrm{Na}^{+}$channels. J Gen Physiol 100:1003-1020.

Weiss F, Paulus MP, Lorang MT, Koob GF (1992) Increases in extracellular dopamine in the nucleus accumbens by cocaine are inversely related to basal levels: effects of acute and repeated administration. J Neurosci 12:4372-4380.

Wheeler DD, Edwards AM, Ondo JG (1993) The effect of cocaine on membrane potential, on membrane depolarization by veratridine or elevated $[\mathrm{K}]_{\mathrm{o}}$ and on sodium/potassium permeability ratios in synaptosomes from the limbic cortex of the rat. Neuropharmacology 32:195-204.

White FJ, Henry DJ, Hu X-T, Jeziorski M, Ackerman JM (1992) Electro- 
physiological effects of cocaine in the mesoaccumbens dopamine system. In: Cocaine: pharmacology, physiology and clinical strategies (Lakoski JM, Galloway MP, White FJ, eds), pp 261-293. Boca Raton: CRC.

White FJ, Hu X-T, Henry DJ, Zhang X-F (1995a) Neurophysiological alterations in the mesocorticolimbic dopamine system during repeated cocaine administration. In: The neurobiology of cocaine: cellular and molecular mechanisms (Hammer Jr RP, ed), pp 95-115. Boca Raton: CRC.

White FJ, Hu X-T, Zhang X-F, Wolf ME (1995b) Repeated administration of cocaine or amphetamine alters neuronal responses to glutamate in the mesoaccumbens dopamine system. J Pharmacol Exp Ther 273:445-454.

White FJ, Hu X-T, Zhang X-F (1997) Dopamine D2 receptors in the ventral striatum: multiple effects of receptor subtypes. Jpn J Psychopharmacol 17:91-95.

Wilson CJ, Kawaguchi Y (1996) The origins of two-state spontaneous membrane potential fluctuations of neostriatal spiny neurons. J Neurosci 16:2397-2410.

Wise RA (1996) Neurobiology of addiction. Curr Opin Neurobiol 6:243-251.

Xu ZC (1995) Neurophysiological changes of spiny neurons in rat neostriatum after transient forebrain ischemia: an in vivo intracellular recording and staining study. Neuroscience 67:823-836.

Zimanyi I, Wang E, Lajtha A, Reith MEA (1989) Effect of cocaine and cocaine congeners on veratridine-induced depolarization in mouse cerebrocortical synaptoneurosomes. J Neurosci Res 22:201-208. 